\title{
Variability of road traffic noise recorded by stationary monitoring stations
}

\author{
Andrzej Bąkowski ${ }^{1, *}$, and Leszek Radziszewski ${ }^{1}$ \\ ${ }^{1}$ Kielce University of Technology, Aleja Tysiąclecia Państwa Polskiego 7, 25-314 Kielce, Poland
}

\begin{abstract}
The paper presents the analysis results of equivalent sound level recorded by two road traffic noise monitoring stations. The stations were located in Kielce (an example of a medium-size town in Poland) at the roads out of the town in the direction of Kraków and Warszawa. The measurements were carried out through stationary stations monitoring the noise and traffic of motor vehicles. The RMS values based on A-weighted sound level were recorded every $1 \mathrm{~s}$ in the buffer and the results were registered every $1 \mathrm{~min}$ over the period of investigations. The registered data were the basis for calculating the equivalent sound level for three time intervals: from 6:00 to 18:00, from 18:00 to 22:00 and from 22:00 to 6:00. Analysis included the values of the equivalent sound level recorded for different days of the week split into $24 \mathrm{~h}$ periods, nights, days and evenings. The data analysed included recordings from 2013. The coefficient of variation and positional variation were proposed for performing comparative analysis of the obtained data scattering. The investigations indicated that the recorded data varied depending on the traffic routes. The differences concerned the values of coefficients of variation of the equivalent sound levels.
\end{abstract}

\section{Introduction}

The Resolution of the European Committee on the requirement of developing, making accessible and updating noise maps has again drawn the attention of communities to environmental noise defined as a factor greatly affecting comfort of life [1]. Noise assessment relies on various measurands, including short- or long-term noise indicators [2]. Acoustic measurements are made at selected sites of the assessment area and last from a few hours to several days. In the next step, models and simulations are used to determine the values of these measurands and their uncertainties. Determining long-term indicators, which should be representative of the whole calendar year, is especially difficult. To this end, traffic noise and vehicle monitoring systems using permanent monitoring terminals were installed in some cities to record the values of the measurands throughout the year. Such systems were constructed in Bydgoszcz, Gdańsk, Kielce, Szczecin, and Wrocław. The outcome of these stations, available on the Internet in real time, describes the changes in traffic structure and volume and indicates hazards arising from the negative effects of noise on people present in a particular part of the city. Kielce has more than ten such stations,

*Corresponding author: abakowski@tu.kielce.pl 
both in the centre and on the outskirts. This study analyses measurement results, the equivalent sound level, recorded by two of the stations. Kielce was chosen as an example of a medium-size town (a population of approximately 200,000) located in the southern part of central Poland. Temperatures within a year range approximately from $-5^{\circ} \mathrm{C}$ in January to $+17^{\circ} \mathrm{C}$ in July. Average monthly precipitation is from $34 \mathrm{~mm}$ in October to $96 \mathrm{~mm}$ in July. The wind, predominantly from the south and west, reaches an average speed of about 10 $\mathrm{km} / \mathrm{h}$ over a year. Kielce gets on average 70 days a year of snow on the ground.

\section{Traffic noise and volume monitoring stations}

The data under analysis were recorded by permanent, automatic sound and traffic volume monitoring stations located in Krakowska Road and in Warszawska Road [3]. Krakowska Road, with four lanes of traffic separated by a 3-m grass median, is the major part of the Kraków-bound thoroughfare functioning as both the transit route and the city street. The structural condition of the bituminous pavement is good. The noise monitoring station is located at the site with the following coordinates $50^{\circ} 51^{\prime} 37.8^{\prime \prime} \mathrm{N}$ and $20^{\circ} 35^{\prime} 41.2^{\prime \prime} \mathrm{E}$. It is situated between two busy intersections. Opposite the road, there is a large handball hall and the bus depot of the Municipal Public Transport Service. The microphone for measuring acoustic pressure is situated at a distance of $4 \mathrm{~m}$ from the edge of the roadway at the height of $4 \mathrm{~m}$.

Data under analysis comes from records for 2013. The database of the recorded data, created in the form of calculated values of the equivalent sound level, comprises 905 records. Due to technical difficulties, the database is not complete and covers only the period between 8 January and 6 December 2013 split into three sub-intervals of a 24-hour interval: day time, evening time and night time. Technical problems in maintaining continuous measurement of data are frequent at $24 \mathrm{~h}$ stations and lead to increased uncertainty as for the measurement results reported.

Warszawska Road is a two-lane road out of Kielce. The function of this road has changed. It was originally designed for heavy vehicle loads. Currently, after transformation, the road is being used mainly for municipal transport and, to a slight extent, as a transit route to Warszawa. The structural condition of the bituminous pavement is good. The noise monitoring station is located at the site with the following coordinates $50^{\circ} 54^{\prime} 15^{\prime \prime} \mathrm{N}$ and $20^{\circ} 40^{\prime} 32^{\prime \prime E}$. The measured equivalent sound level data from this station cover the 2012 to 2013 period, with the sample size of 1022 records.

The monitoring terminals mounted in Kielce include a sound level meter, a safety camera and a weather station. The acoustic measurements were carried out using SVAN 958A device, which is a four-channel digital vibration analyser and a class 1 sound level meter, operating within the measuring frequency range $0.5 \mathrm{~Hz}$ to $20 \mathrm{kHz}$, depending on a microphone used. The microphone for the acoustic pressure measurements is mounted at a distance of $4 \mathrm{~m}$ from the edge of the road at a height of $4 \mathrm{~m}$. The measuring microphone used in this study was a Microtech Gefell MK250 free-field, prepolarised 1/2" condenser microphone with a sensitivity of $50 \mathrm{mV} / \mathrm{Pa}, \mathrm{SV} 12 \mathrm{~L}$ preamplifier, a frequency range $3,5 \mathrm{~Hz}$ to $20 \mathrm{kHz}$ and a dynamic range from $15 \mathrm{~dB}$ to $146 \mathrm{~dB}$. The temperature range within which the device is operable is from $-50^{\circ} \mathrm{C}$ to $100^{\circ} \mathrm{C}$. The resolution of the signal RMS detector is $0.1 \mathrm{~dB}$. The measurements were carried out 24 hours a day. The RMS values of the A sound level were registered in the buffer every $1 \mathrm{~s}$ and the results were recorded every 1 minute. The equivalent sound level was calculated on this basis for three time intervals, i.e., from 6:00 to 18:00, from 18:00 to 22:00 and from 22:00 to 6:00. Traffic volume was measured with a digital radar $245 \mathrm{MHz}$ by WAVETRONIX. Weather data were recorded by the VAISALA WTX 510 automatic meteorological station. 


\section{Measurement results}

Examples of the equivalent sound level data recorded by the monitoring stations in Krakowska and Warszawska roads are shown in Fig. 1.

a)

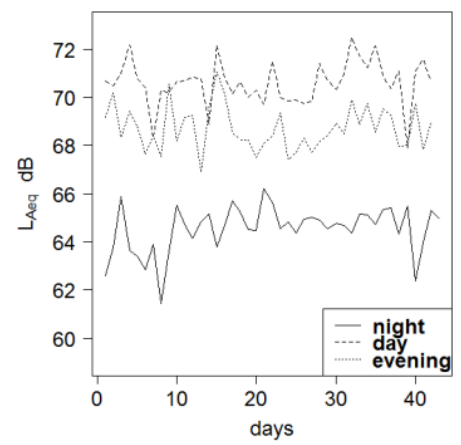

b)

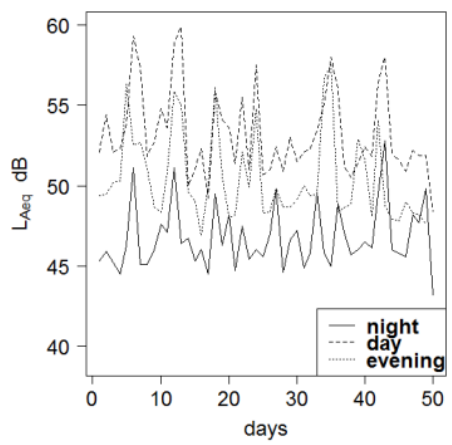

Fig. 1. Equivalent sound level $\mathrm{L}_{\text {Aeq }}$, split into time sub-intervals for Mondays in 2013, recorded in Kielce a) Krakowska Rd, b) Warszawska Rd.

Analysis of the $\mathrm{L}_{\text {Aeq }}$ curves in Fig. 1 and of the box plots in Fig. 2 shows that in most cases, the distribution of the analyzed variable values is not normal. Also, compared with Warszawska Road, the $\mathrm{L}_{\text {Aeq }}$ parameter in Krakowska Road has noticeably higher values, by about $16 \mathrm{~dB}$. In all cases, the data show certain values that can be regarded as atypical (outliers). This phenomenon is thus characterized by high randomness, which is consistent with the findings reported in the literature [4].
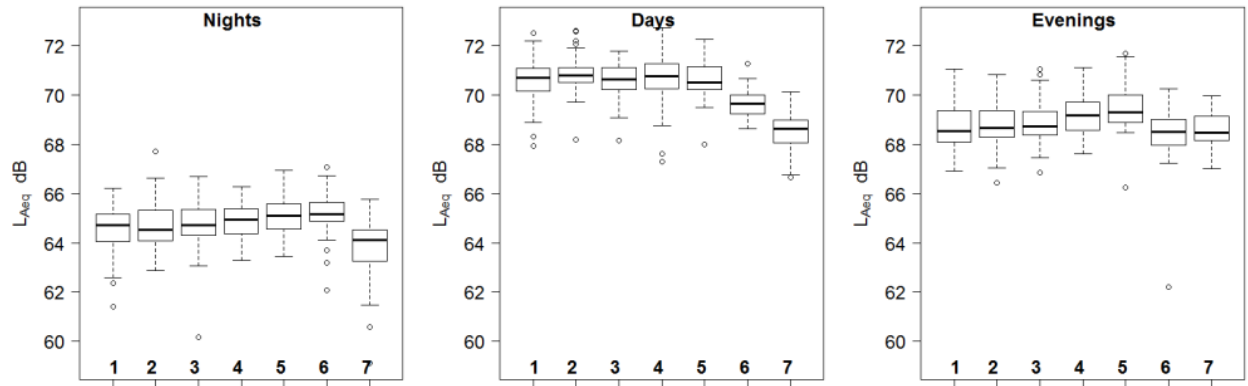

Fig. 2a. Equivalent sound level, $L_{\text {Aeq }}$, split into time sub-intervals for all week days in 2013, recorded in Kielce - Krakowska Rd., (denotation: 1 - Monday, 2 - Tuesday, 3 - Wednesday, 4 - Thursday, 5 - Friday, 6 - Saturday, 7 - Sunday). 

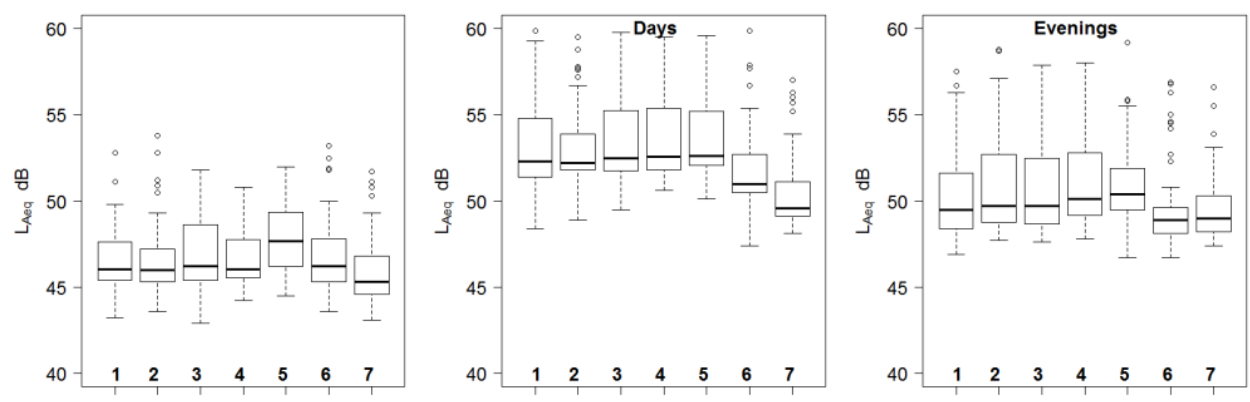

Fig. 2b. Equivalent sound level, $\mathrm{L}_{\text {Aeq }}$, split into time sub-intervals for all week days in 2013, recorded in Kielce - Warszawska Rd.

The most commonly used measurand for the assessment of $\mathrm{L}_{\mathrm{Aeq}, \mathrm{T}}$ expressed in terms of decibels, is defined as follows:

where:

$$
\mathrm{L}_{\mathrm{Aeq}, \mathrm{T}}=10 \cdot \log \left[\frac{1}{\mathrm{~T}} \int_{0}^{\mathrm{T}}\left(\frac{\mathrm{p}_{\mathrm{A}}(\mathrm{t})}{\mathrm{p}_{0}}\right)^{2} \mathrm{dt}\right]=10 \cdot \log \left[\left(\frac{\mathrm{p}_{\mathrm{A}_{\mathrm{RMS}}}}{\mathrm{p}_{0}}\right)^{2}\right]
$$

$T$ - is the total time of measurement, $\mathrm{s}$

$p_{A}(t)$ - is the A-weighted acoustic pressure,

$p_{0}-$ is the reference acoustic pressure, standardized as $20 \mu \mathrm{Pa}$.

The non-linear character of logarithmic function changes is a limitation that impedes the determination of, for example, standard deviation or measurement uncertainty. Therefore, the authors of this paper decided to determine the RMS sound pressure in the T period from equation 1 and use this parameter in further analysis.

$$
\mathrm{p}_{\mathrm{A}_{\mathrm{RMS}}}=\mathrm{p}_{\mathrm{A}}=\sqrt{10^{\left(0.1 \cdot \mathrm{L}_{\mathrm{Aeq}, \mathrm{T}}\right)} \cdot \mathrm{p}_{0}^{2}}
$$

In this study, the authors analysed the measurement data expressed in terms of $\mathrm{Pa}$ to be able to compare the fixed components (the mean and the median) and variable components (deviation from the mean) of the signals recorded. The logarithmic scale of the equivalent sound level $\left(\mathrm{L}_{\mathrm{Aeq}, \mathrm{T}}\right)$ can hinder a direct comparison of measurement data.

Figure 3 and Table 1 summarize the calculated RMS values, $\mathrm{p}_{\mathrm{A}_{\mathrm{RMS}}}$, for Krakowska and Warszawska roads (on Mondays).
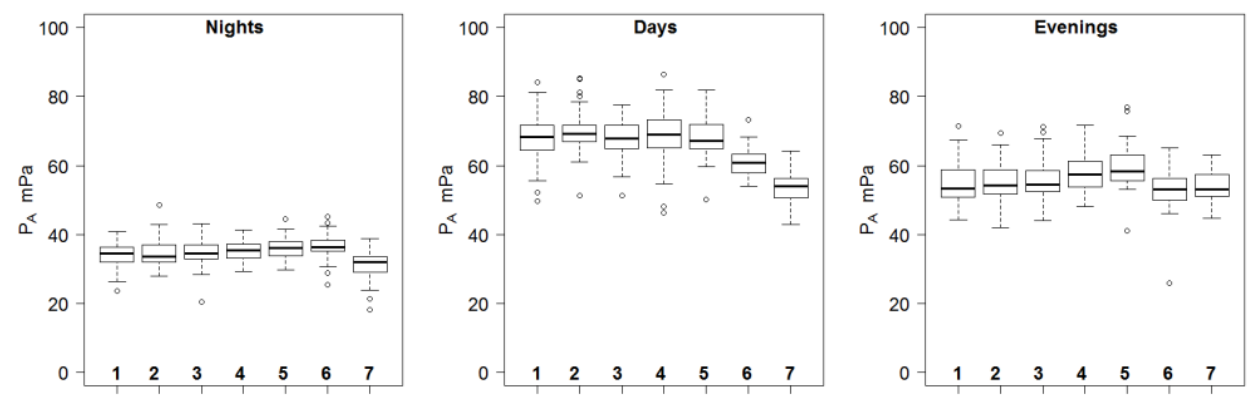

Fig. 3a. Root means square (RMS) acoustic pressure for days of the week split into time sub-intervals, recorded in 2013 in Krakowska Rd. 

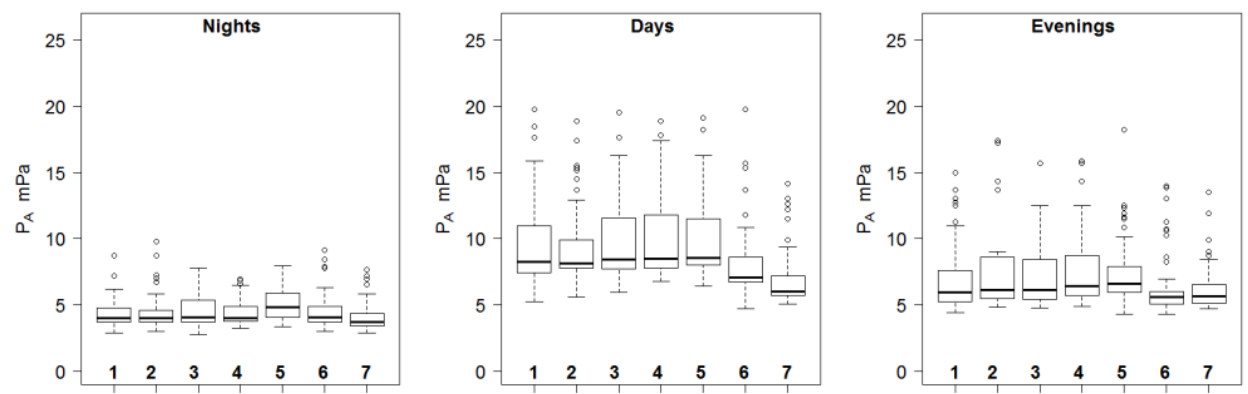

Fig. 3b. Root means square (RMS) acoustic pressure for days of the week split into time sub-intervals, recorded in 2013 in Warszawska Rd.

The median, the mean value, standard deviation, the coefficient of variation, the quartile deviation and the positional variation used further in the analysis were determined from the following dependencies. The mean value of $\mathrm{p}_{\mathrm{A}_{\mathrm{RMS}}}$ can be determined as the expected value:

$$
\overline{\mathrm{p}_{\mathrm{A}_{\mathrm{RMS}}}}=\frac{1}{\mathrm{n}} \sum_{\mathrm{i}=1}^{\mathrm{i}=\mathrm{n}} \mathrm{p}_{\mathrm{A}_{\mathrm{RMS}}}
$$

Standard deviation of the measurement data can be determined from:

$$
\sigma_{\mathrm{p}_{\mathrm{A}_{\mathrm{RMS}}}}=\sqrt{\frac{1}{\mathrm{n}-1} \sum_{\mathrm{i}=1}^{\mathrm{i}=\mathrm{n}}\left(\mathrm{p}_{\mathrm{A}_{\mathrm{RMS}}}-\overline{\mathrm{p}_{\mathrm{A}_{\mathrm{RMS}}}}\right)^{2}}
$$

The acoustic pressure variation was determined using the coefficient of variation, quartile deviation [5] and positional variation. The coefficient of variation can be calculated from:

$$
\operatorname{COV}_{\mathrm{p}_{\mathrm{A}_{\mathrm{RMS}}}}=\mathrm{COV}=\frac{\sigma_{\mathrm{p}_{\mathrm{A}_{\mathrm{RMS}}}}}{\overline{\mathrm{p}_{\mathrm{R} \mathrm{RS}}}} \cdot 100 \%
$$

This coefficient is a relative, dimensionless measure of acoustic pressure dispersion. The quartile deviation was determined from:

$$
\mathrm{Q}_{31}=0.5 \cdot\left(\mathrm{Q}_{3}\left(\mathrm{p}_{\mathrm{A}_{\mathrm{RMS}}}\right)-\mathrm{Q}_{1}\left(\mathrm{p}_{\mathrm{A}_{\mathrm{RMS}}}\right)\right)
$$

Quartile deviation is an absolute but dimensional measure of acoustic pressure dispersion. When referred to the median, quartile deviation gives positional variation, which can be determined from:

$$
\mathrm{V}_{\mathrm{Q}}=\frac{\mathrm{Q}_{31}}{\mathrm{Med}}
$$


Table 1. Root means square (RMS) acoustic pressure $\mathrm{p}_{\mathrm{A}_{\mathrm{RMS}}}$ recorded on Mondays at Krakowska and Warszawska sites.

\begin{tabular}{|c|c|c|c|c|c|c|c|c|}
\hline Time interval & $\begin{array}{l}\text { Med } \\
\text { mPa }\end{array}$ & $\begin{array}{c}\overline{\mathbf{p}_{\mathbf{A}_{\mathrm{RMS}}}} \\
\mathbf{m P a}\end{array}$ & $\begin{array}{c}\sigma_{\mathbf{p}_{\mathbf{A}_{\mathrm{RMS}}}} \\
\mathbf{m P a}\end{array}$ & $\underset{\%}{\operatorname{COV}}$ & $\begin{array}{c}\mathbf{Q}_{31} \\
\mathrm{mPa}\end{array}$ & $\begin{array}{l}\mathbf{V}_{\mathbf{Q}} \\
\%\end{array}$ & $\begin{array}{l}\text { SW } \\
\text { test }\end{array}$ & $\begin{array}{c}\text { JB } \\
\text { test }\end{array}$ \\
\hline \multicolumn{9}{|c|}{ Krakowska Rd. } \\
\hline $24 \mathrm{~h}$ interval & 52.67 & 52.18 & 15.32 & 29.36 & 14.53 & 27.59 & 0.00 & 0.03 \\
\hline Night time & 34.48 & 33.89 & 3.59 & 10.60 & 2.15 & 6.23 & 0.20 & 0.11 \\
\hline Day time & 68.36 & 68.19 & 7.19 & 10.54 & 3.46 & 5.06 & 0.24 & 0.70 \\
\hline Evening & 53.34 & 54.89 & 5.96 & 10.86 & 3.89 & 7.29 & 0.19 & 0.21 \\
\hline \multicolumn{9}{|c|}{ Warszawska Rd. } \\
\hline $24 \mathrm{~h}$ interval & 6.18 & 7.06 & 3.34 & 47.28 & 1.75 & 28.32 & 0.00 & 0.00 \\
\hline Night time & 4.01 & 4.47 & 1.15 & 25.82 & 0.52 & 12.96 & 0.00 & 0.00 \\
\hline Day time & 8.24 & 9.65 & 3.42 & 35.39 & 1.71 & 20.75 & 0.00 & 0.00 \\
\hline Evening & 5.97 & 7.04 & 2.66 & 37.76 & 1.17 & 19.60 & 0.00 & 0.00 \\
\hline
\end{tabular}

Table 1 compiles the values of the medians, the expected values, standard deviation, the coefficient of variation, quartile deviation, positional variation and the results of Shapiro-Wilk (SW) and Jarque-Bera (JB) tests. Note that the COV is calculated using every recorded observation, including those that may be outliers. Thus, the outliers are not eliminated unless the positional measure of variation, $V_{Q}$, is used. Its numerator is calculated by subtracting the first quartile from the third quartile $\left(\mathrm{Q}_{31}\right)$, covering the middle $50 \%$ of the recorded data.

The Shapiro-Wilk test and the Jarque-Bera test provided sufficient evidence to reject the null hypothesis about normal distribution of the $\mathrm{p}_{\mathrm{A}_{\mathrm{RMS}}}$ parameter for Warszawska Road, whereas no such evidence was found for Krakowska Road.

The values of $\mathrm{L}_{\text {Aeq }}$ recorded on subsequent Mondays in 2013 at the Krakowska Road site are compiled in Fig. 1a. The diagram indicates that on some days the $\mathrm{L}_{\text {Aeq }}$ parameter increases or decreases noticeably, especially at the time interval denoted as "day time". Analysis of the equivalent sound level for the $24 \mathrm{~h}$ period at the Krakowska Road site in 2013 indicated that the mean value of $\mathrm{L}_{\mathrm{Aeq}, \mathrm{T}}$ was about $67.9 \mathrm{~dB}$. The $\mathrm{L}_{\mathrm{Aeq}, \mathrm{T}}$ values change with week days and time sub-intervals, as shown in Fig. 2a. Figure 2a summarizes the box plots for the year 2013 data but split into week days and $24 \mathrm{~h}$ sub-intervals: night time, day time and evenings. The diagrams show that the median of equivalent sound level:- for night times increases slightly from Monday to Saturday up to $65 \mathrm{~dB}$ and decreases on Sunday by about $1 \mathrm{~dB}$, for day times is about $71 \mathrm{~dB}$ from Monday to Friday and decreases to about $69 \mathrm{~dB}$ on Saturday, for evening time is about $68 \mathrm{~dB}$ on Monday, Tuesday, Wednesday, Saturday and Sunday and increases on Thursday and Friday by $1 \mathrm{~dB}$.

Analysis of the $\mathrm{L}_{\text {Aeq }}$ values recorded on subsequent Mondays of 2013 shown in Fig. 1b indicated that at the Warszawska site irregular variability over time is close to the impulse variability. This phenomenon is evident for the data recorded for each time sub-interval several points can be indicated at which $\mathrm{L}_{\mathrm{Aeq}}$ is higher by at least $5 \mathrm{~dB}$ that the neighbouring values. Analysis of the equivalent sound level for the $24 \mathrm{~h}$ period at the Warszawska Road site in 2013 indicated that the mean value of $\mathrm{L}_{\mathrm{Aeq}, \mathrm{T}}$ was about $50 \mathrm{~dB}$. These values vary with week days and time sub-intervals. Figure $2 b$ summarizes the box plots for the year 2013 data but split into week days and 24h sub-intervals: night time, day time and evenings. The diagrams show that the median of equivalent sound level: for night times on Monday, Tuesday, Wednesday, Thursday, Saturday and Sunday is $46 \mathrm{~dB}$ and increases by $2 \mathrm{~dB}$ on Friday, for day times is about $52 \mathrm{~dB}$ from Monday to Friday and decreases to about $49 \mathrm{~dB}$ on Saturday and Sunday, for evenings is about $49 \mathrm{~dB}$ on Monday, 
Tuesday, Wednesday, then increases by $2 \mathrm{~dB}$ on Thursday and Friday to decrease up to $49 \mathrm{~dB}$ on Saturday and Sunday.

On Saturday and Sunday evenings, the monitoring station recorded a lot of high-value atypical data. Analysis of the median values for all the data from 2013 and for the subintervals within the $24 \mathrm{~h}$ interval, Fig. 2, indicates the following differences:

1. Warszawska Road - between day-night time sub-intervals: $5.9 \mathrm{~dB}$, between day-evening time sub-intervals: $2.5 \mathrm{~dB}$, and between evening-night time sub-intervals: $3.4 \mathrm{~dB}$

2. Krakowska Road - between day-night time subintervals:5.6 dB, between day-evening time sub-intervals: $1.6 \mathrm{~dB}$, and between evening-night time sub-intervals: $4 \mathrm{~dB}$.

Analysis of changes in the $V_{Q}$ value indicates that it was the lowest for the night time subintervals in both roads. Its highest value was recorded in Krakowska Road for the evening sub-intervals and in Warszawska Road for day time sub-intervals.

\section{Conclusions}

Comparison of the data obtained from both stations shows clear differences between the

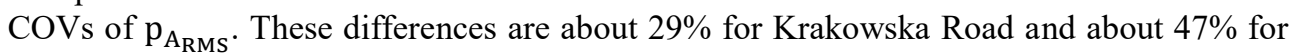
Warszawska Road. A considerable difference, of about $18 \mathrm{~dB}$, was also observed between the medians of the equivalent sound level. Analysis of the medians, with measurement uncertainty taken into account, for the sub-intervals indicates that regardless of the monitoring station site, the differences between the values of the equivalent sound level are as follows: about $6 \mathrm{~dB}$ between day-night sub-intervals, $2 \mathrm{~dB}$ between day-evening subintervals, and about $4 \mathrm{~dB}$ between evening-night subintervals.

The coefficient of variation calculated for the $\mathrm{p}_{\mathrm{A}_{\mathrm{RMS}}}$ parameter at the Krakowska Road site was about 29\%, and for the Warszawska Road site about 47\%, as shown in Table 1. The values of this parameter for particular sub-intervals vary but in Warszawska Road they are always about three times as high as in Krakowska Road. It has to be noted that higher interquartile ranges $Q_{31}$ were observed for Krakowska Road. However, the relative values of the interquartile ranges, related to the median (positional variation $\mathrm{V}_{\mathrm{Q}}$ ), were higher in the case of Warszawska Road (comparable values were obtained only for $24 \mathrm{~h}$ intervals)

\section{References}

1. Directive 2002/49/Ec of the European Parliament and of the Council, Official Journal of the European Communities - 18.07.2002

2. A. Jagniatinskis, B. Fiks, O. Zaporozhets, Procedia Engineering 134, 301-308 (2016)

3. A. Bąkowski, L. Radziszewski, Z. Skrobacki, Procedia Engineering 177, 281-288 (2017)

4. B. Przysucha, W. Batko, A. Szeląg, Arch. Acoust. 40, 183-189 (2015)

5. A. Bąkowski, L. Radziszewski, M. Žmindak, Procedia Engineering 177, 297-302 (2017) 